\title{
A study on awareness and acceptance of contraceptive methods in postpartum women in a tertiary care institute
}

\author{
Sowmyanarayanan Lavanya, Rajyalakshmi Talapala*, Swetha Munivenkatappa
}

Department of Obstetrics and Gynaecology, Narayana Medical College Hospital, Nellore, Andhra Pradesh, India

Received: 08 October 2020

Revised: 20 October 2020

Accepted: 21 October 2020

\section{*Correspondence:}

Dr. Rajyalakshmi Talapala,

E-mail: drrajyalakshmitalapala@gmail.com

Copyright: (c) the author(s), publisher and licensee Medip Academy. This is an open-access article distributed under the terms of the Creative Commons Attribution Non-Commercial License, which permits unrestricted non-commercial use, distribution, and reproduction in any medium, provided the original work is properly cited.

\section{ABSTRACT}

Background: Contraception is an important tool to reduce unwanted pregnancy and promote healthy living. The benefits of family planning program are recognized worldwide to improve health, social and economic status of families. The objective of the study is to estimate the prevalence of awareness for various contraceptive methods among postpartum women, to find the acceptance of different contraceptive methods and evaluate the factors affecting the same.

Methods: The study is a cross-sectional observational study conducted among postpartum women who delivered in Narayana medical college hospital over a period of 1 year. The awareness, acceptance and reason or refusal for contraception was assessed. The data obtained was analyzed to generate graphs and tables.

Results: A total of $61 \%$ women were aware of at least one method of contraception. $74 \%$ were using a contraceptive at the time of study. $39 \%$ were unaware of any contraceptive method. $49 \%$ preferred intrauterine contraceptive device. Main reason for non-acceptance of contraceptive was couple's desire for a male child. Health professionals were the main source of imparting the knowledge of birth spacing.

Conclusions: Regular antenatal counselling to all pregnant women must be done in every hospital in a village to tertiary care centres. Information should be provided about various contraceptive methods and patient should be able to choose a method of her own choice. A strong motivation is required to adopt a suitable method individualised to each woman.

Keywords: Contraception, Postpartum, Intra uterine contraceptive device

\section{INTRODUCTION}

Contraception is an important tool to reduce unwanted pregnancy and promote healthy, better living among women. India was the first in the world to initiate the national family planning program in the year 1951 with the objective of "reducing the birth rate to the extent necessary to stabilize the population at a level consistent with requirement of national economy." The drastic population growth in India calls for steps to stabilize India's population. ${ }^{1}$ The benefits of family planning program have become increasingly recognized worldwide, for improvement in health, social, economic status of families and improve the public health by reducing the maternal and neonatal mortality and morbidity. ${ }^{2}$ Contraception includes both temporary and permanent measures, designed to prevent pregnancy and promote small family norm.

India was the first to formulate national population policy, 2000 but still, India lags in practicing contraception to the fullest and limiting the family size. ${ }^{3}$ As on March 1, 2011, India's population stood at 1.21 billion comprising of 623.72 million $(51.54 \%)$ males and 586.47 million $(48.46 \%)$ females. India, which accounts for world's $17.5 \%$ population, is the second most 
populous country in the world next to China $(19.4 \%) .{ }^{4}$ By slowing the growth of the population, families are able to devote more resources to each child, resulting in selfsufficient growth. Women become more self-reliant and poverty in the country declines. Despite the known benefits of family planning, globally more than 120 million women aged 15 to 49 who are married or in a union have an unmet need for family planning. Family planning could prevent up to one- third of all maternal deaths by allowing women to delay motherhood, space births, avoid unintended pregnancies, unsafe abortions and stop pregnancies when they reached their desired family size. ${ }^{5}$ Evidence shows that closely-spaced pregnancies pose health risks to mothers and new-borns. An analysis of data from the demographic and health survey (DHS) for various years shows that babies born less than two years are prone to neonatal mortality when compared to babies born after three years. Women with shorter inter-pregnancy intervals are at a higher risk of maternal mortality, post-partum hemorrhage, preterm delivery, and anemia. Half a million women die every year due to complications related to pregnancy and childbirth in developing countries across the world. Of the 7.7 million child deaths reported worldwide in 2010, around $22 \%$ of deaths have occurred in India. This study is to assess the level of adoption of contraception among women who had delivered within one year and to identify the different variables that affect postpartum contraception. Newly parturient mothers are primarily concerned about their health and the new-born's health. Even though contraceptive usage has increased over a decade, there exists a KAP-gap, i.e., a gap between the knowledge, attitude, and practices regarding contraception. ${ }^{6}$ Women are receptive to family planning education in postpartum, and they generally do not return for contraception once discharged from the hospital. Therefore, the immediate post-partum period is most crucial to counsel them and assure their contraceptive acceptance during their hospital stay in order to prevent unwanted pregnancy and curb population growth as well. Lactational amenorrhoea method (LAM) can prevent pregnancy to a certain extent though not protective completely. Transition from LAM to other modern contraceptive methods becomes a necessity to prevent pregnancy. Antenatal and immediate post-partum counselling in the hospital ensures a good decision making for the couple regarding family planning.

The objectives of the study were to estimate of the prevalence of awareness for various contraceptive methods among postpartum women and to find the usage and acceptance of different types of contraceptive methods and evaluate the various factors affecting the same.

\section{METHODS}

This is a prospective cross-sectional questionnaire-based study carried out in the Department of Obstetrics of Narayana Medical college hospital, Nellore, Andhra
Pradesh, India between May 2019 and April 2020. A total of 1000 postpartum women were enrolled in the study. The sample size was calculated by using prevalence of usage of contraceptive methods in married women. Total number of married women of age group 15-49 is $22 \%$. With allowable error of $10 \%$, using the formula for calculating sample size i.e. $n=3.84 \mathrm{pq} / \mathrm{L} 2$ where $\mathrm{P}$ is the prevalence, the minimal sample size of 340 was obtained. The study period taken was for a period of 1 year and hence 1000 women attending the postpartum clinic were selected by systematic random sampling. All postpartum women were briefed about the study and their consent was taken to be enrolled in the study. They were interviewed based on a predesigned questionnaire. The questionnaire elicited information regarding their age, educational status, income, awareness, and practice of the various male and female, temporary and permanent methods of contraception. They were counselled and allowed to choose a method of contraception of their choice. Postpartum women were selected randomly, fulfilling inclusion and exclusion criteria.

\section{Inclusion criteria}

Inclusion criteria were, postpartum women within six weeks of delivery seeking contraceptive advice, women opting for immediate postpartum temporary contraception, postpartum women opting for a permanent method of sterilization, women who agree to sign an informed consent form.

\section{Exclusion criteria}

Exclusion criteria were women more than a year since last child birth, women who do not agree to sign an informed consent form

A questionnaire was prepared after extensive literature search and for content validity, it was sent to 3 experts in the field and independent reviews obtained. Patients were given pre-decided questions for answering to know their awareness of contraceptive methods.

The data obtained were analyzed using SPSS software version 17.0 to generate graphs and tables. The percentage was calculated for all descriptive statistics.

\section{RESULTS}

Among the 1000 women included in the study, $49 \%$ of the women were in the age group of 15-24 years, $41 \%$ belonged to the age group of 25-35 years and 10\% of women were above 35 years of age.

Educational qualification of the women studied showed that $51 \%$ were illiterates, $14 \%$ of women had done primary schooling, 7\% had done secondary schooling, $8 \%$ had higher secondary school education and $20 \%$ had degree qualification. 
$73 \%$ of the women in the study were housewives and $27 \%$ were working group with regard to the occupational status.

The socio-economic status of the women pointed that $10 \%$ of the women belonged to upper- class, $9 \%$ belonged to upper-middle class, $59 \%$ belonged to lower middle class, $13 \%$ belonged to upper lower class and $9 \%$ belonged to lower class.

In our study $57 \%$ of women were from rural areas and $43 \%$ were from urban areas of nellore.

The distribution of women according to the parity showed that $53 \%$ of women were P1L1, 36\% were P2L2, $9 \%$ were P3L3 and 2\% had more than 3 issues.

With regard to the awareness about contraception, 61\% of the postpartum women were aware of various existing contraceptive methods and $39 \%$ of the postpartum women were ignorant of any method.

Analysis of the awareness of the different methods of contraception pointed that $89 \%$ of women were aware of female sterilization method, $77 \%$ had idea about condoms, $76 \%$ had knowledge of Intra uterine contraceptive device, $43 \%$ had idea of progesterone only pills, $9 \%$ were aware of male sterilization, $8 \%$ had idea of natural methods and 5\% knew about injectables.
In our study, a detailed analysis of the source of information about contraceptive methods for the postpartum women was done and found that $28 \%$ of the women had the information through mass media (TV, radio, and newspapers), 4\% through interaction with friends, $12 \%$ from motivation by husbands, $11 \%$ from family members' advice \& 47\% from the health professionals' initiative and counselling (Figure 1).

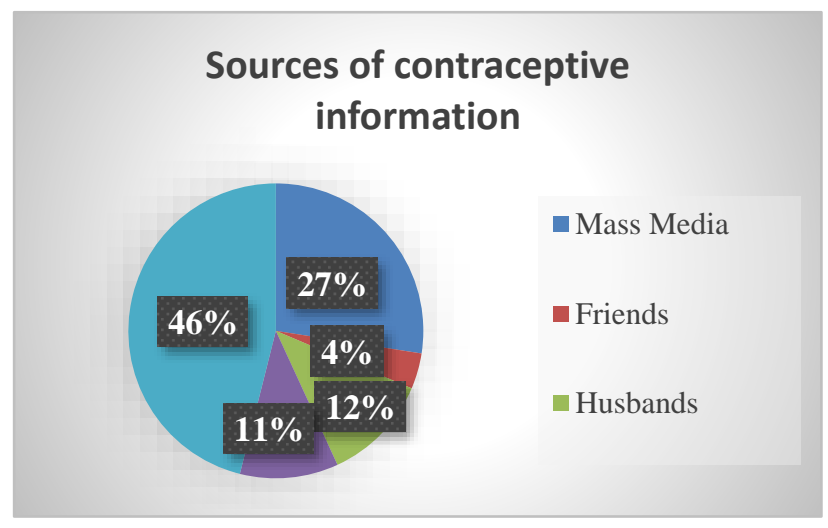

Figure 1: Sources of various contraceptive methods.

After thorough counseling, 82\% of the postpartum women gave acceptance to the contraceptive methods and $18 \%$ declined to accept any method.

Table 1: Awareness, earlier use and acceptance sociodemographic profile.

\begin{tabular}{|c|c|c|c|c|}
\hline \multirow[t]{2}{*}{ Socio demographic } & $\begin{array}{l}\text { No. of cases } \\
(n=1000)\end{array}$ & $\begin{array}{l}\text { Awareness } \\
(n=610)\end{array}$ & $\begin{array}{l}\text { Earlier use } \\
(n=300)\end{array}$ & $\begin{array}{l}\text { Acceptance } \\
(\mathbf{n}=\mathbf{8 2 0})\end{array}$ \\
\hline & $\mathbf{N}(\%)$ & $\mathbf{N}(\%)$ & $\mathbf{N}(\%)$ & $\mathbf{N}(\%)$ \\
\hline \multicolumn{5}{|l|}{ Age (years) } \\
\hline $15-24$ & $490(49)$ & $230(46.9)$ & $115(23.5)$ & $340(69.38)$ \\
\hline $25-35$ & $410(41)$ & $310(75.60)$ & $160(39)$ & $390(95.12)$ \\
\hline$\geq 35$ & $100(10)$ & $70(70)$ & $25(25)$ & $90(90)$ \\
\hline \multicolumn{5}{|l|}{ Educational status } \\
\hline Illiterate & $510(51)$ & $200(39.21)$ & $80(16)$ & $390(76.47)$ \\
\hline Primary School & $140(14)$ & $110(78.57)$ & $50(36)$ & $110(78.57)$ \\
\hline Secondary school & $70(7)$ & $50(71.42)$ & $25(35)$ & $55(78.57)$ \\
\hline Higher secondary school & $80(8)$ & $60(75)$ & $35(43)$ & $70(87.5)$ \\
\hline Degree and above & $200(20)$ & $190(95)$ & $110(55)$ & $195(97.5)$ \\
\hline \multicolumn{5}{|l|}{ Occupation } \\
\hline Housewife & $730(73)$ & $350(47.94)$ & $160(22)$ & $555(76.02)$ \\
\hline Working & $270(27)$ & $260(96.29)$ & $140(52)$ & $265(98.14)$ \\
\hline \multicolumn{5}{|l|}{ Socio-economic status } \\
\hline Upper & $100(10)$ & $90(90)$ & $65(65)$ & $95(95)$ \\
\hline Upper middle & $90(9)$ & $70(77.77)$ & $35(39)$ & $80(88.88)$ \\
\hline Lower middle & $590(59)$ & $310(52.54)$ & $140(24)$ & $480(81.35)$ \\
\hline Upper lower & $130(13)$ & $80(61.53)$ & $35(27)$ & $100(76.92)$ \\
\hline Lower & $90(9)$ & $60(66.66)$ & $25(28)$ & $65(72.22)$ \\
\hline \multicolumn{5}{|l|}{ Residence } \\
\hline Rural & $570(57)$ & $200(35.08)$ & $90(15)$ & $400(70.17)$ \\
\hline Urban & $430(43)$ & $410(95.34)$ & $210(49)$ & $420(97.67)$ \\
\hline
\end{tabular}




\begin{tabular}{|lllll|} 
Socio demographic & $\begin{array}{l}\text { No. of cases } \\
(\mathbf{n = 1 0 0 0 )}\end{array}$ & $\begin{array}{l}\text { Awareness } \\
(\mathbf{n = 6 1 0 )}\end{array}$ & $\begin{array}{l}\text { Earlier use } \\
(\mathbf{n = 3 0 0 )}\end{array}$ & $\begin{array}{l}\text { Acceptance } \\
\mathbf{( n = 8 2 0 )}\end{array}$ \\
\hline Parity & $\mathbf{N}(\mathbf{\%})$ & $\mathbf{N}(\mathbf{\%})$ & $\mathbf{N}(\mathbf{\%})$ \\
\hline 1 & & & & $380(71.69)$ \\
\hline 2 & $530(53)$ & $174(32.83)$ & $95(18)$ & $330(91.66)$ \\
\hline 3 & $360(36)$ & $340(94.44)$ & $119(33)$ & $90(100)$ \\
\hline$\geq 4$ & $90(9)$ & $80(88.88)$ & $70(78)$ & $20(100)$ \\
\hline
\end{tabular}

The reason for non-acceptance of contraceptive methods were analysed and found that $30 \%$ of women declined the use in view of expectation of a male child, $25 \%$ had fear of side effects, $11 \%$ were comfortably not using any method as husband was staying away, rest of them were not using any method abiding the family decision, due to ignorance and few relied on natural methods (Table 2).

Table 2: Reasons for non-acceptance of contraceptive methods.

\begin{tabular}{|lll|}
\hline Reason & $\begin{array}{l}\text { No. of } \\
\text { cases } \\
(\mathbf{n}=\mathbf{1 8 0})\end{array}$ & Percentage \\
\hline Lack of knowledge & 19 & 10.5 \\
\hline Fear of side effects & 47 & 26 \\
\hline Rely on natural methods & 16 & 8.8 \\
\hline Husband staying away & 21 & 11 \\
\hline Family decision & 20 & 11.11 \\
\hline Preference of male child & 57 & 31 \\
\hline
\end{tabular}

In the study population, $43 \%$ of women gave acceptance to intrauterine contraceptive device (IUCD), 32\% agreed for female sterilization, $7 \%$ accepted progesterone only pills, 7\% accepted using condoms, 4\% agreed for injectable contraception, 3\% opted for natural methods and $2 \%$ agreed for male sterilization (Figure 2).

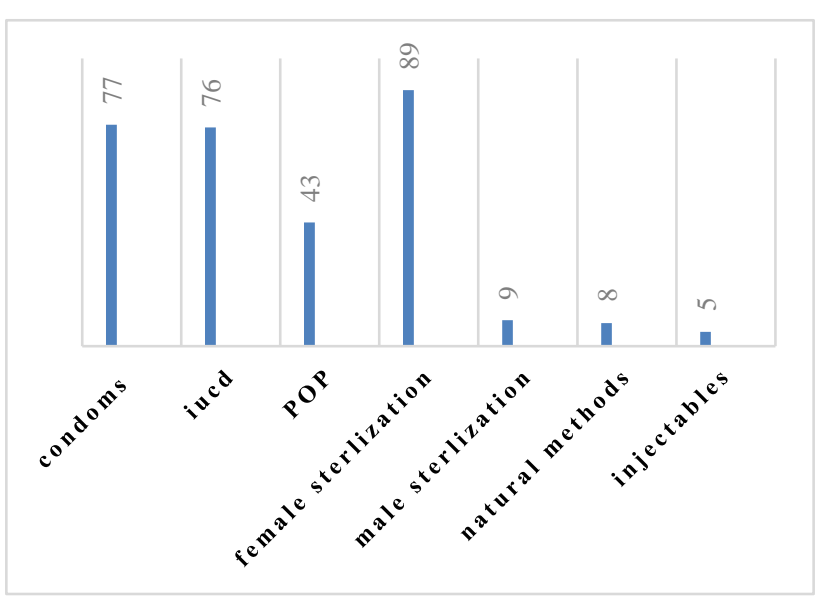

Figure 2: Awareness of various contraceptive methods.

Table 1 show that the awareness, earlier use, and acceptance were higher in the age group of 26 to 30 years. It was observed that as age advances, awareness and acceptance of contraception and sterilisation also increase. Awareness and acceptance were highest in the educated, working women and higher socioeconomic groups. In our study, urban population were more aware of the methods and accepted contraceptives well as compared to rural population. Acceptance was highest in women with two to three children. Maximum number of women were aware of female sterilization (89\%) followed by condoms $(77 \%)$ and intrauterine device (76\%) and progesterone-only pill (43\%).

\section{DISCUSSION}

Postpartum women are more likely to have an unmet need for family planning.

Demographic and health surveys (DHS) conducted in 27 developing countries have stated that during the extended postpartum period, up to a year after delivery, most women wished to delay the subsequent pregnancy for 2-3 years or prevent any further pregnancies altogether. Women with an unmet need for family planning were defined as those who have had a recent delivery, thus presumed to be fecund, and report not wanting any more children or pregnancy at all or wanting to delay the delivery of their next child, but not using any contraceptive method. It has been suggested that such women should adopt some contraceptive method as early as possible after delivery and before the sexual activity.

The postpartum women were educated about the benefits of contraceptive methods through individual approach, mass approach \& group discussions.

Educational interventions can help increase the knowledge of contraceptive methods, enabling individuals to make informed decisions and use contraception more effectively.

A lack of knowledge of contraceptive methods and a source of supply, cost, and poor accessibility are the barriers that exist in developing countries.

In our study, majority of women, $74 \%$ were in the age group of 21 to 30 years. The high figures in young women are due to the practice of early marriages in our study population in rural areas. Nowadays the younger women are more conscious about their health and more 
receptive towards postpartum contraception. The agewise distribution also shows that the contraceptive awareness and usage increase as the age increases. Saini et al reported maximum number of users of spacing methods were in the age group of 20 to 29 years $(63.7 \%)^{7}$

Literacy has a deep impact on acceptance of small family norm as indicated in our study too where literates accept contraception broadly well.

Working women had more knowledge about contraceptive methods when compared to homemakers. In the present study, contraception usage is less in housewives due to the lack of awareness of different contraceptive methods, and this situation is overcome by effective counseling of postpartum women in their local languages, group discussions, via posters, and visuals.

$59 \%$ of the women in the study belong to the lower middle class, which is close to the study done by Gaikwad RA et al upper-class women had more awareness of contraceptive methods due to higher educational qualifications and interactions.

In our study, awareness, earlier use, and acceptance were more in urban areas as compared with rural areas similar to Thyagarajan et al. ${ }^{8}$ Reason for this is due to easy availability of pills, higher literacy level, better socioeconomic conditions, and easy access to health facilities in urban areas. Chaudhary reported that urban residence strongly influenced contraceptive use. ${ }^{9}$ The survey done in District Level Household and Facility points that $62 \%$ of urban population used contraceptives as compared with $38 \%$ in rural population. ${ }^{10}$ The key barriers in rural areas were poor spousal communication, socio-cultural norms (especially the husband's role as primary decision-maker and the desire for a large family) and fear of side effects. 53\% of women in the study group are primipara, which is close to the study done by Singh $\mathrm{M}$ et al as the parity increases the acceptance level also increases.

Most of the women got the awareness of the various contraceptive methods from the health professionals $(47 \%)$. i.e., doctors, nurses, auxiliary nurse midwife (ANM), anganwadi worker (AWW) which is close to the study conducted by Bhartisahu et al so, in our study health professionals, play an important role in imparting the knowledge of contraception. Sharma et al reported $49 \%$ of women seeking advice from health professionals followed by $41 \%$ from mass media. ${ }^{11}$ An Ethiopian study showed that $80.3 \%$ of health personnel contributed in providing information regarding contraception.

In our study, $61 \%$ of postpartum women were aware of at least one of the family planning methods, which is comparable to the study done by Thapa et al $(69 \%){ }^{12}$ Ghike et al $(67.5 \%)$ concluded that the best and widely known method of family planning was female sterilization (89\%), which is comparable to that of National Family Health Survey (NFHS)-3 (98\%) as well as a survey conducted in Andhra Pradesh (82.1\%). ${ }^{13}$ The contraceptive prevalence rate among postpartum women in our study was $74 \%$. According to NFHS-3, the prevalence of modern contraceptive method in state is $56 \%$, which is similar to that of India as a whole (56\%). ${ }^{14}$ Our study shows that the next familiar methods among women are condoms and cu-T. Coinciding with many other studies, the observation made was postpartum women had the least awareness about natural methods and male sterilization in spite of so many government programs implemented in the family welfare department. It implies, still more effort is needed in this regard. The contraceptive acceptance showed rising trends with increasing age, educational status, and family income. This is similar to the findings of a study conducted by Singh et al in Delhi. ${ }^{15}$ The main reasons for nonacceptance of contraception were preference of male child $(30 \%)$ and lack of knowledge $(24 \%)$. Singh et al reported fear of side effect $(24 \%)$ as the major reason in their study, followed by expectation of a male child ( $8 \%)$, while Mahmood et al in their study reported lack of knowledge $(32.5 \%)$ as the main reason for not using contraceptives. ${ }^{16}$ Fear of side effects of contraceptives is the main reason for not continuing it. It can be reduced by proper selection of contraceptive before starting its use and adequate comfort given in the follow up visits.

After giving information about various family planning methods, women were asked for their own choice, and maximum number of women preferred IUCD (43\%) as their first choice followed by female sterilization (32\%), progesterone only pills, condoms, natural methods, injectables and male sterilisation. In a study by Shrivastav et al $(71.2 \%)$, choices preferred by postpartum women were: $33.6 \%$ opted for IUCD, $20 \%$ for barrier method, $26.5 \%$ for Depo-Provera, $10 \%$ for progesterone pill, $3.9 \%$ preferred lactational amenorrhea method, and safe method $3 \% .^{17}$

The present study highlights the need to strengthen information education communication (IEC) activities and family planning services to be provided in the immediate post-partum period before the discharge of women from the hospital to ensure the contraceptive acceptance and its appropriate use among them. It would curb unwanted pregnancies that lead to unsafe abortion and maternal mortality. A sustained effort to increase awareness and motivation for contraceptive use is recommended. It can be brought about by facilitating access to more information, education, and communication in antenatal women. The most important factor is the regular availability of contraceptives and adequate health care services, even at the peripheral level. It is inferred that the services are to be strengthened at the rural level and focus of counselling and education should be shifted to uneducated, housewives and illiterate women who need strong motivation to adopt contraception. 


\section{Limitations}

This study was that only a group of patients who seek health care and advice in a tertiary centre were interviewed. Hence, the finding in this study cannot be generalized to the whole state or to India as a whole. There is a need for proper promotion of spacing method by policymakers and field workers and motivation of couples to accept them so as to have healthy and wealthy India.

\section{CONCLUSION}

It was observed from the present study that there is a lack of awareness of contraception in postpartum women. Regular counselling is a must to all pregnant women from every health care centre in a village to super speciality centres in cities. There is a lack of awareness of emergency contraception in postpartum women under study. There is a dire need to strengthen the family planning services at all levels. It is essential to devise programs to spread awareness among women to use contraception to limit births and implement postpartum family planning programs in India by integrating them with maternal and child health services. Antenatal period is the perfect time to impart the knowledge of contraception, birth spacing and family planning as the couples develop confidence in the treating doctor during the visits and rely on their advice. Postpartum period is a golden time when the advice given by the health care professional has maximum acceptance by the patient and implementation is higher, which restores her health for a life time. There is a need for proper promotion of spacing method by policymakers and field workers and motivation of couples to accept them so as to have a healthy and wealthy India.

\section{ACKNOWLEDGMENTS}

I acknowledge and thank all the women enrolled in the study for their fullest cooperation. I thank all the workers and staff involved in mobilizing the resources needed for the study. I thank my post graduates who have extended their hand for the conduct of the study and to follow up the patients.

\section{Funding: No funding sources}

Conflict of interest: None declared

Ethical approval: The study was approved by the Institutional Ethics Committee

\section{REFERENCES}

1. New Delhi: Registrar General \& Census Commissioner of India. Census of India, 2011.
Available at: http://censusindia.gov.in. Accessed on 05 May 2020.

2. Conde-Agudelo A, Belizan JM. Maternal morbidity and mortality associated with inter-pregnancy interval: a cross-sectional study. Br Med J. 2000; 321(7271):1255-9.

3. National population policy 2000 , cited 3rd march 1991.

4. Size, growth rate and distribution of populationcensus of India. 2011.

5. Shah IH, Say L. Maternal mortality and maternity care from 1990 to 2005: uneven but important gains. Reprod Health Matt. 2007;15(30):17-27.

6. Ashoke S, John S, Jayanti MT. The KAP-Gap in Nepal: reasons for non-use of contraception among couples with an unmet need for family planning. Asia-Pac Popul J. 2000;6(1):25-38.

7. Saini NK, Singh M, Gaur DR, Kumar R. Awareness and practices regarding spacing methods in urban slums of Rohtak. Indian $\mathbf{J}$ Comm Med. 2006;31(2):84-5.

8. Thyagarajan S, Reji B, Viswan SP. Determinants of contraceptive usage in India. Int $\mathbf{J}$ Interdiscipl Multidiscipl Stud. 2014;1(10):88-97.

9. Chaudhary RH, The influence of female education, labour force participation and age at marriage on fertility behavior in Bangladesh. Soc Biol. 1984; 31(1-2):59-74.

10. International institute of population science (IIPS). District Level Household and Facility Survey (DLHS-3), 2007-08: India. Mumbai: IIPS; 2010.

11. Sharma SK, Pratap KC, Ghimire DR. Ethnic differentials of the impact of the Family Planning program on contraceptive use in Nepal. Demogr Res. 2011;25(27):837-68.

12. Thapa S, Rani A, Mishra CP. Knowledge, attitude and belief about contraception in post-partum and post abortal women in a tertiary care centre. Int $\mathbf{J}$ Reprod Obstet Gynaecol. 2014;3(3):533-9.

13. Ghike S, Joshi S, Bhalerao A, Kawthalkar A. Awareness and contraception practices among women an Indian rural experience. J Sout Asia Federat Obstet Gynaecol. 2010;2(1):19-21.

14. National Family Health Survey (NFHS-3), India Available at: http://rchiips.org/nfhs/nfhs3.shtml. Accessed on 05 May 2020.

15. Singh M, Mehla S, Ranjan R, Das B. Awareness and acceptance of contraception in post-partum women in a tertiary care hospital Delhi. Int J Reprod Obstet Gynaecol. 2015;4(3):690-5.

16. Mahmood SE, Srivastava A, Shrotriya VP, Shaifali I, Mishra P. Postpartum contraceptive use in rural Bareilly. Ind J Commun Heal. 2011;23(2):56-7.

17. Shrivastav A, Khan MS, Chauhan CR. Knowledge, attitude and practices about contraceptive among married reproductive females. Int $\mathbf{J}$ Sci Stud. 2014;1(5).

Cite this article as: Lavanya S, Talapala R, Munivenkatappa S. A study on awareness and acceptance of contraceptive methods in postpartum women in a tertiary care institute. Int J Reprod Contracept Obstet Gynecol 2020;9:4648-53. 